\title{
Homoplasies, Consistency Index and the Complexity of Morphological Evolution: Catfishes as a Case Study for General Discussions on Phylogeny and Macroevolution
}

\author{
Homoplasias, Índice de Consistencia y la Complejidad de la Evolución Morfológica: \\ Peces Gato como un Estudio de Caso para Discusiones Generales en Filogenia y Macroevolución \\ *,** Rui Diogo
}

DIOGO, R. Homoplasies, consistency index and the complexity of morphological evolution: Catfishes as a case study for general discussions on phylogeny and macroevolution. Int. J. Morphol., 25(4):831-837, 2007.

SUMMARY: Catfishes constitute a highly diversified, cosmopolitan group that represents about one third of all freshwater fishes and is one of the most diverse Vertebrate taxa. The detailed study of the Siluriformes can, thus, provide useful data, and illustrative examples, for broader discussions on general phylogeny and macroevolution. In this short note I briefly expose how the study of this remarkably diverse group of fishes reveals an example of highly homoplasic, complex 'mosaic' morphological evolution.

KEY WORDS: Catfishes; Homoplasies; Morphological macroevolution; Phylogeny; Siluriformes; Teleostei.

\section{INTRODUCTION}

The catfishes, or Siluriformes, found in North, Central and South America, Africa, Europe, Asia and Australia, with fossils inclusively found in Antarctica, constitute a highly diversified, cosmopolitan group, which, with more than 2700 species, represents about one third of all freshwater fishes and is one of the most diverse Vertebrate taxa (e.g. Burgess, 1989; Diogo, 2003; Teugels, 2003). The detailed study of the Siluriformes can, thus, provide useful data, and illustrative examples, for broader discussions on evolutionary biology (Diogo, 2004). In this aspect, one of the points that most struck me in my research on these fishes in the last years is the rather high level of homoplasy and complexity of their morphological evolution.

Catfishes as an example of complex, mosaic morphological evolution. This subject, it should be noticed, is deeply related with my own personal scientific development. When I first started the observations and comparisons on catfishes, the impression was that a great part of the evolutionary changes concerning the major morphological systems of those fishes were somewhat 'oriented', in a somewhat 'simple' way. Of course, I felt the incredible complexity and diversity of catfishes, a complexity and diversity surely resulting from several homoplasic events. This was precisely the main reason to choose this amazing group of fishes as a case study for discussing general topics on phylogeny and macroevolution. But the exam of more and more morphological phylogenetic characters in numerous catfishes, reaching to a total of 440 characters in 87 genera representing all the 32 extant families of the order, and specially the subsequent results obtained from the cladistic analysis of those 440 characters (Diogo, 2004), clearly pointed out a particularly complex macroevolutionary scenario. The strict-consensus cladogram obtained in that cladistic analysis, of which the main results are briefly summarised in Figure 1 showing the relationships between the extant catfish families, had a lenght of 902 steps and a Consistency Index (CI) of 0.52 (see Diogo, 2004). That is, within the characters analysed, of each two evolutionary morphological transitions, one is, in an approximate way, due to homoplasy.

One could eventually argue that such a level of homoplasy could perhaps be exclusively related with an eventual incorrectness of the phylogenetic results obtained in the cladistic analysis of Diogo (2004). However, the

\footnotetext{
* Museo Nacional de Ciencias Naturales de Madrid, Spain.

** Laboratory of Functional and Evolutionary Morphology, University of Liège, Belgium.
} 
discussion is not so simple. The CI value obtained in Diogo's 2004 work is significantly higher, for example, than the CI value obtained in the two other published cladistic studies on catfish higher-level phylogeny, which in fact included less phylogenetic characters than Diogo's work (Mo, 1991, included 126 characters and had a CI of 0.36, de Pinna, 1998, included 239 characters and had a CI of 0.41). Thus, if instead of the phylogenetic results of Diogo (2004) one would take the phylogenetic results of these two other cladistic studies, the level of homoplasy would even be greater. Also, a CI of 0.52 is markedly superior to that expected for a random distribution of 440 morphological characters in 87 different terminal taxa of a so diverse and complex group as the Siluriformes, thus theoretically revealing a strong phylogenetic signal (see Sanderson \& Donoghue, 1989). In reality, the study of catfishes effectively seems to provide an example of rather homoplasic, complex 'mosaic' morphological macroevolution.

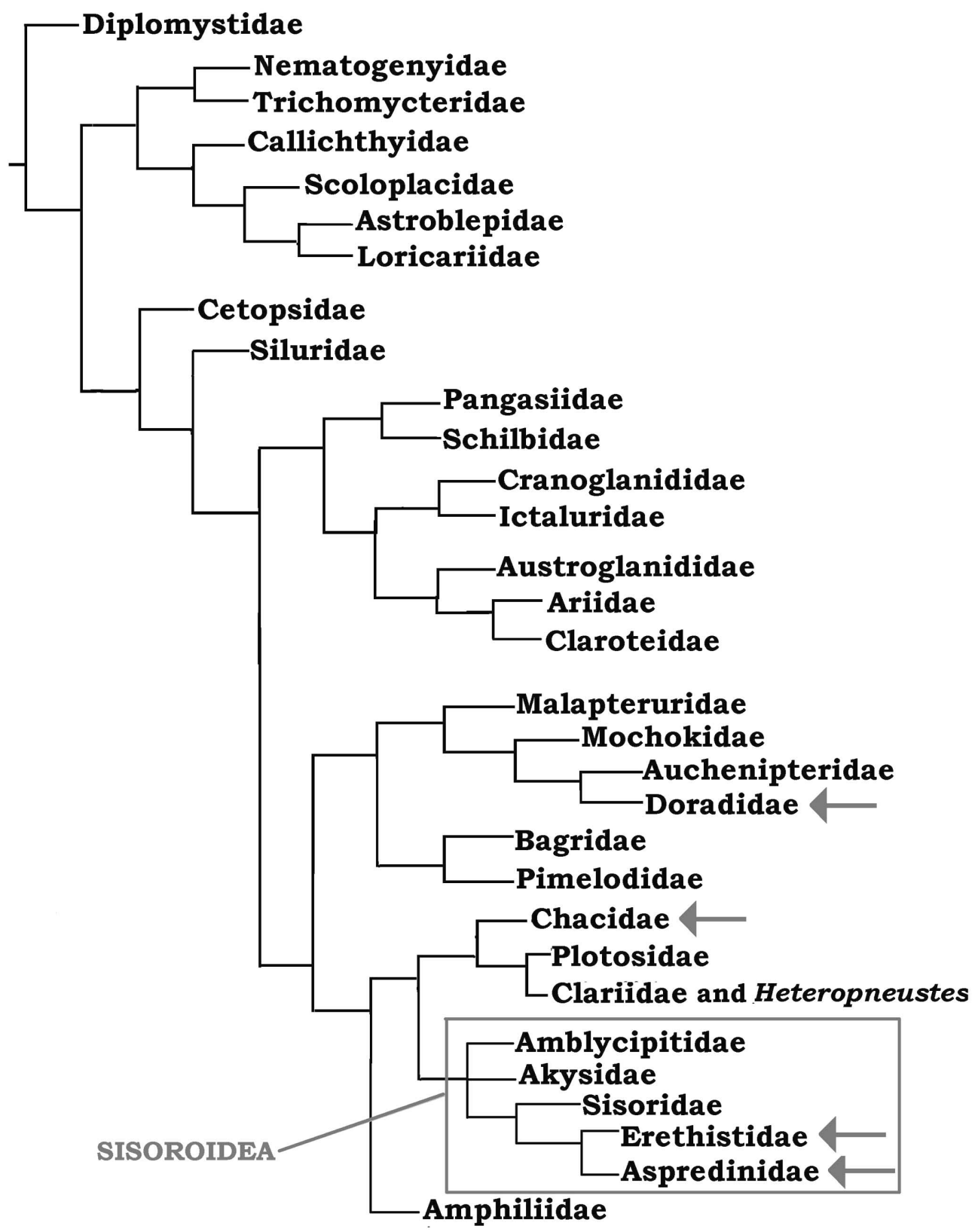

Fig. 1- Relationships among the extant siluriform families, according to Diogo's (2004) cladistic analysis on the higher-level phylogeny of the order [for more details, see text]. 
The rather complex and 'mosaic' morphological evolution of catfishes can be illustrated by a practical example concerning one of the best supported clades within the order: that formed by the Asian Sisoroidea (Amblycipitidae, Akysidae, Sisoridae and Erethistidae) and the South American Aspredinidae (see Fig. 1) (Ferraris, 1989; Mo; de Pinna, 1993, 1996, 1998; Chen, 1994; Diogo et al., 2001; Diogo, 2004). The first author providing evidence to suggest that the South American aspredinids were related to Asiatic taxa was Ferraris. Mo, in the first explicitly phylogenetic analysis of siluriform higher-level phylogeny, supported this view, placing the aspredinids as either basal to or in a polytomy with a clade containing the Asian amblycipitids, akysids and sisorids. Somewhat similar hypotheses were suggested subsequently by de Pinna (1993), who placed the Aspredinidae in a polytomy also including these three Asian groups, as well as the Amphiliidae from Africa and the Loricarioidea from South America. In 1994, Chen provided further evidence to place the Aspredinidae as the sister group of a clade composed of the Asian families Amblycipitidae, Sisoridae and Akysidae. This hypothesis was subsequently strongly supported by de Pinna (1996), who considered that the Sisoridae of previous authors was a paraphyletic assemblage, with a subunit of it (which he named Erethistidae: see Fig. 1) being more closely related to the South American Aspredinidae than to the remaining sisorid taxa. This view was posteriorly corroborated in de Pinna's (1998) overview on the phylogenetic relationships of Neotropical catfishes. The cladistic analysis of the author of the present work (Diogo, 2004) on siluriform higher-level phylogeny strongly supported the hypothesis of de Pinna (1996), with the Neotropical Aspredinidae being grouped in a monophyletic clade together with the Asian Sisoridae and Erethistidae, as shown in Figure 1.

Thus, there is strong evidence accumulated in the last 15 years supporting a close relationship between the South American Aspredinidae and the Asian Sisoroidea families Amblycipitidae, Akysidae, Sisoridae and particularly Erethistidae (see Fig. 1). To briefly summarise, the main synapomorphic characters supporting the clade Amblycipitidae + Akysidae + Sisoridae + Erethistidae + Aspredinidae are: the 'parapophysis of the $5^{\text {th }}$ vertebra markedly strong and perpendicular to vertebral axis'; the 'presence of an humero-vertebral ligament connecting the humeral process of the cleithrum and the anterior vertebrae'; the 'presence of a well-developed anteromesial process of the cleithrum'; and the 'ventral tip of first dorsal fin pterygophore and corresponding neural spines with contacting facets'. The main synapomorphies supporting the clade Sisoridae + Erethistidae + Aspredinidae are: the 'humero-vertebral ligament attaching posteriorly on the parapophysis of the $5^{\text {th }}$ vertebra and anteriorly on the hume- ral process'; the 'presence of a long and thin ligament between the dorsal surface of the sesamoid bone 1 of the suspensorium and the posteroventral surface of the autopalatine'; and the 'parapophysis of the $5^{\text {th }}$ vertebra markedly expanded laterally'. Lastly, the main synapomorphic features supporting the clade Erethistidae + Aspredinidae are: the 'presence of a fossa between the dorsomedial limb of the posttemporosupracleithrum and the parieto-supraoccipital'; the 'internal support for pectoral fin rays markedly small in size'; and the 'anterior portion of lateral line running closely to lateral margin of Weberian lamina' (see the overview provided by Diogo, 2004, for more details on this subject).

Attending to the strong evidence supporting the close relationship between the Aspredinidae and the Asian Sisoroidea families Amblycipitidae, Akysidae, Sisoridae and particularly Erethistidae, it is thus very interesting to notice that, as stressed by de Pinna (1998), the aspredinids share some "striking" derived anatomical features with other catfish groups such as the Chacidae or the Doradidae (see Fig. 1).

The aspredinids and the chacids share, effectively, some rather peculiar, rare morphological characters that, attending to the strong evidence supporting the clade Sisoroidea (Fig. 1), were seemingly acquired independently. In particular, the configuration of the posterodorsal region of the skull in the members of these two families is remarkably similar, as stressed Chardon (1968). For example, both these groups present a well-developed, deep fossa between the posttemporo-supracleithrum, the parieto-supraoccipital and, eventually, the epioccipital (see Fig. 2). Such a fossa is only found, besides these groups, in the Sisoroidea erethistids (see Fig. 2). Also, both the Aspredinidae and Chacidae present a well-developed, dorsal lamina of the Weberian apparatus contacting with the dorsal surface of the body (see Fig. 2), a feature not found elsewhere in the Siluriformes. Another peculiar, and also rather rare, feature present in the Aspredinidae and the Chacidae is the markedly thin and mesially extended dorsomesial limb of the posttemporo-supracleithrum (see Fig. 2 ), which, apart these two groups, is only found in the Sisoroidea akysid genus Parakysis. But the morphological similarities between chacids and aspredinids are not only restricted to the configuration of the structures of the posterodorsal region of the cranium. For instance, in both these groups the prevomer is missing (see Fig. 2). The absence of the prevomer is a highly peculiar and rare character among the order Siluriformes, only occurring in a few other catfishes such as, for example, the members of the pimelodid genus Microglanis and of the scoloplacid genus Scoloplax. According to Chardon, the anatomical similarity between the chacids and the aspredinids could probably be associated to a homoplasic adaptation to a peculiar 'burying' behaviour exhibited by the members of these two groups. 
DIOGO, R. Homoplasies, consistency index and the complexity of morphological evolution: Catfishes as a case study for general discussions on phylogeny and macroevolution. Int. J. Morphol., 25(4):831-837, 2007.

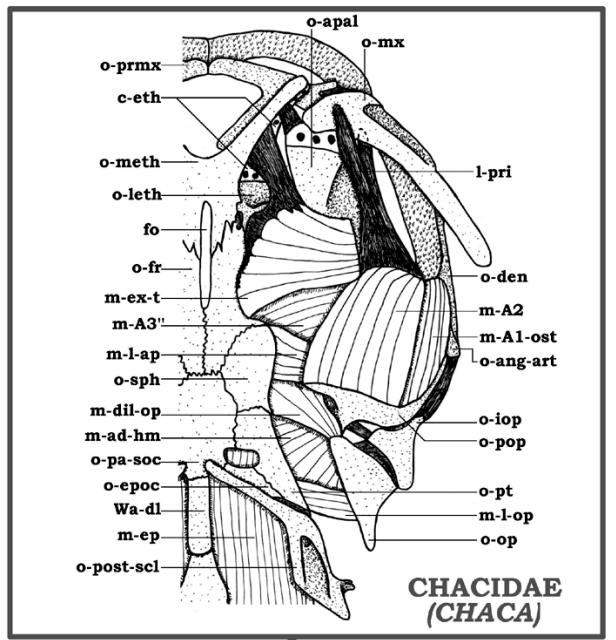

Fossa between posttemporo-supracleithrum and parieto-supraoccipital Dorsal lamina of Weberian apparatus contacting dorsal surface of body Thin,medially extended dorsomedial limb of posttemporo-supracleithrum.

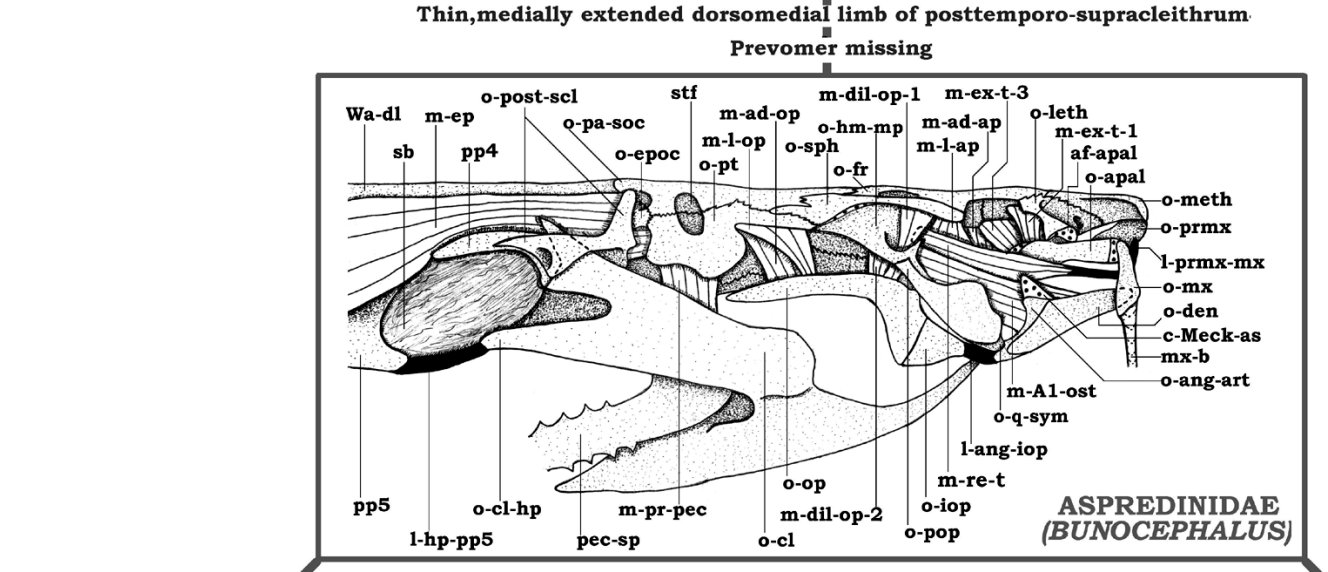

Prominent dorsolateral projections of mesethmoid Undifferentiated mesocoracoid arch

Prominent anterior process of dorsal condyle of pectoral spine

Well-developed anteroventral lamina of preopercle

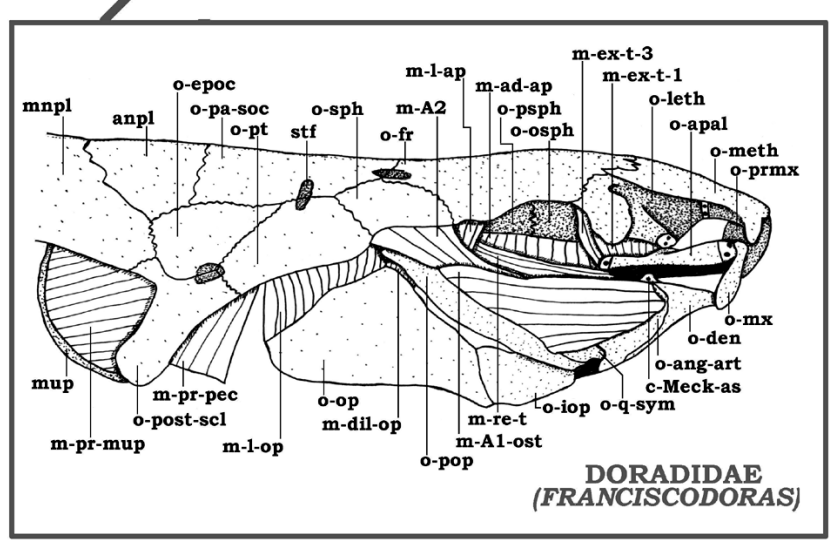

Fossa between posttemporo-supracleithrum and parieto-supraoccipital Parapophysis 5 stout, perpendicular to vertebral axis Ligament between humeral process of cleithrum and anterior vertebrae Parapophysis 5 markedly expanded laterally Internal support for pectoral fin rays markedly small in size Long ligament between sesamoid bone 1 and back of autopalatine

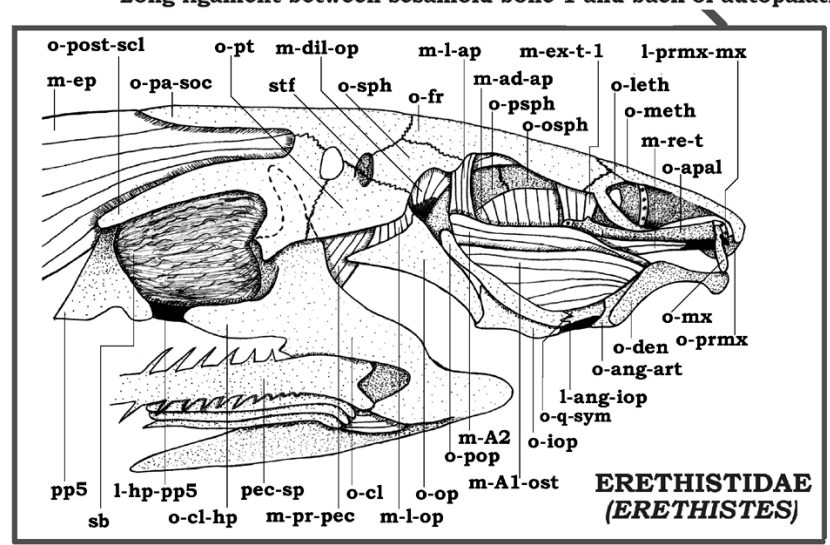


Fig. 2- Scheme illustrating some major derived morphological features present in the Aspredinidae and Chacidae, in the Aspredinidae and Doradidae, and in the Aspredinidae and Erethistidae, respectively (the cephalic region of the aspredinid, the doradid and the erethistid catfishes illustrated in the figure is shown in lateral view; the cephalic region of the dorsoventrally compressed chacid catfishes illustrated is shown in dorsal view) [for more details, see text]. af-apal, articulatory face for autopalatinum; anlp, anterior nuchal plate; c-eth, cartilago ethmoideum; c-Meck-as, ascending portion of cartilago Meckeli; fo, fontanel; 1-ang-iop, ligamentum angulo-interoperculare; 1hp-pp5, ligamentum humero-vertebrale; 1-pri, ligamentum primordium; 1-prmx-mx, ligamentum praemaxillo-maxillare; m-A1-ost, mA2, m-A3", sections of musculus adductor mandibulae; m-ad-ap, musculus adductor arcus palatini; m-ad-hm, musculus adductor hyomandibularis; m-ad-op, musculus adductor operculi; m-dil-op, musculus dilatator operculi; m-dil-op-1, m-dil-op-2, sections of musculus dilatator operculi; m-ep, musculus epaxialis; m-ex-t-1, m-ex-t-3, sections of musculus extensor tentaculi; m-l-ap, musculus levator arcus palatini; m-l-op, musculus levator operculi; m-pr-mup, musculus protractor of the Mullerian process; m-pr-pec, musculus protractor pectoralis; m-re-t, musculus retractor tentaculi; mnlp, mesial nuchal plate; mup, Mullerian process; mx-b, maxillary barbel; o-ang-art, os angulo-articulare; o-apal, os autopalatinum; o-cl, os cleithrum; o-cl-hp, humeral process of os cleithrum; o-den, os dentale; o-epoc, os epioccipitale; o-fr, os frontale; o-hm-mp, os hyomandibulo-metapterygoide; o-iop, os interoperculare; o-leth, os latero-ethmoideum; ometh, os mesethmoideum; o-mx, os maxillare; o-op, os operculare; o-osph, os orbitosphenoideum; o-pa-soc, os parieto-supraoccipitale; o-pop, os praeoperculare; o-post-scl, os posttemporo-supracleithrum; o-prmx, os praemaxillare; o-pt, os pteroticum; o-psph, os pterosphenoideum; o-q, os quadratum; o-sph, os sphenoticum; pec-sp, pectoral spine; pp4, pp5, parapophysis 4 and 5; sb, swimbladder; stf, supratemporal fossa; Wa-dl, dorsal lamina of Weberian apparatus.

But, as mentioned above, the rather "mosaic", complex combination of peculiar characters present in the Aspredinidae makes that these fishes also share some remarkable peculiar features with other non-Sisoroidea groups that are morphologically very different from the Chacidae, as, for example, the Doradidae. Some of these characters concern, for example: the prominent dorsolateral projections of laminar bone of the mesethmoid; the mesocoracoid arch and the main body of the scapulocoracoid being undistinguished from each other; the presence of the highly developed anterior process of dorsal condyle of pectoral spine; and the presence of the welldeveloped anteroventral lamina of the preopercle (see Fig. 2 ). These characters, and other features, have inclusively lead Friel (1994) to propose a close relationship between the aspredinid and the doradoid catfishes (i.e., the clade constituted by the Doradidae, the Auchenipteridae and the Mochokidae: see Fig. 1). However, as explained above, the phylogenetic results of Ferraris, Mo, de Pinna (1993, 1996, 1998), Chen, Diogo et al. (2001) and Diogo (2004) seem to indicate that the peculiar derived features shared, on the one hand, by aspredinids and chacids and, on the other hand, by aspredinids and doradids, are, in reality, due to homoplasy.

In fact, the point that I would like to stress here is that, even if all those phylogenetic studies supporting the close relationship between the Aspredinidae and the Asian Sisoroidea (see Fig. 1) were wrong, and, for instance, the aspredinids were eventually more closely related to the chacids, or, alternatively, to the doradids, this would still imply, anyway, the occurrence of numerous homoplasic events between the Aspredinidae and other catfish groups.

The situation could be briefly illustrated as follows. Let's take a 'triangle' with the Aspredinidae in the center and with (1) the Asian Sisoroidea family Erethistidae, (2) the Doradidae, and (3) the Chacidae in the extremities of the triangle, respectively (see Fig. 2). The works of Ferraris, Mo, de Pinna (1993, 1996, 1998), Chen, Diogo et al. (2001) and Diogo (2004) strongly support a close relationship between the Aspredinidae and the Asian Sisoroidea (Fig. 1). Thus, the remarkable peculiar similarities found between, in the one hand, the Aspredinidae and the Doradidae, and, in the other hand, the Aspredinidae and the Chacidae, are thus assigned to homoplasic events, thus revealing a particularly complex, 'mosaic' homoplasic evolution within these groups (see Fig. 2). However, if, alternatively, one would accept the hypothesis Aspredinidae + Doradidae, one would have to admit an even greater number of homoplasic events to explain the peculiar morphological features shared by aspredinidids and erethistids, as well as a series of homoplasies occurring between the aspredinids and the chacids (see Fig. 2). Lastly, if one would accept the hypothesis Aspredinidae + Chacidae, one would have to admit that the great number of apomorphic morphological peculiarities shared by aspredinidids and erethistids would be the result of homoplasy, and that there are several homoplasies occurring between the aspredinidids the and doradids (see Fig. 2).

Therefore, the point is that the choice of any extremity of this 'triangle' would imply necessarily a series of homoplasic events between the Aspredinidae and the groups represented in the other two extremities. In reality, as explained above, the phylogenetic scenario proposed by the studies of Ferraris, Mo, de Pinna (1993, 1996, 1998), Chen, Diogo et al. (2001) and Diogo (2004) (Aspredinidae + Asian Sisoroidea) is the one that requires a smaller number of homoplasic events. Thus, the high level of homoplasy illustrated in this example cannot simply be explained by the choice of an erroneous phylogenetic scenario, but rather 
by a seemingly truly, highly complex 'mosaic' morphological evolution.

This example also illustrates an important point that has been stressed by authors such as e.g. Farris $(1983,1989)$, Sanderson \& Donoghue (1989), Klassen et al. (1991), Wilkinson (1991), Kallersjö et al. (1999), Simonetta (1999), Kitching et al. (1998), Marques \& Gnaspini (2001) and Felsenstein (2003) but that is often misinterpreted. As stated by Klassen et al. (1991: 446), the "amount of homoplasy exhibited by a cladogram is usually considered inversely proportional to the confidence that an investigator will have in both the tree and the data set from which it was derived". However, such a 'confidence measurement' only makes full sense when comparing levels of homoplasy exhibited by cladograms concerning a somewhat similar number of characters referring to a similar type of data set in a same biological group. Indeed, there is no reason to think that all different biological groups, even of a relatively similar size (i.e. with a somewhat similar number of species), exhibit exactly the same levels of homoplasy. If one obtains a certain consistency index $\mathrm{A}$ in the cladogram of a group $\mathrm{X}$ and this index $\mathrm{A}$ is smaller than that of a cladogram B concerning a group $\mathrm{Y}$, there is no reason to consider, a priori, even if the number of taxa and characters analysed in both cases is somewhat similar, that the cladogram B is 'probably more likely' than the cladogram A. For example, as stressed Marques \& Gnaspini (2001), some groups of cave animals seem to exhibit a particularly high level of homoplasy. So, as stated in the premises of the cladistic paradigm, but sometimes confused in practice, a cladogram with a relatively small consistency index could eventually be simply related with the occurrence of a truly high level of homoplasy in the group to which the cladogram refers, and not necessarily to a 'bad cladogram'. The interpretation of the information given in a cladistic analysis by homoplasy indexes such as the consistency index should thus be made with much caution, case by case, taking into account not only the number of characters and of terminal taxa included in the cladistic analysis, but also the type of characters and the biological group to which the cladistic analysis refers.

ACKNOWLEDGMENTS: I thank J. Cambray (Albany Museum of Grahamstown), G.G. Teugels (Musée Royal de l'Afrique Centrale), P. Laleyé (Université Nationale du Bénin), R. Vari, J. Williams and S. Jewett (National Museum of Natural History) and P. Duhamel (Muséum National D'Histoire Naturelle) for kindly providing a large part of the biological material used in my studies of catfishes during the last years. I would also like to acknowledge I. Doadrio, I. Peng, G.G. Teugels, R.P. Vari, S. Weitzman, T. Abreu, A. Zanata, B.G. Kapoor, F. Meunier, S. He, D. Adriaens, F. Wagemans, C. Oliveira, E. Parmentier, and specially M.M. de Pinna, P. Skelton, M.J.L. Stiassny, F.J. Poyato-Ariza, G. Arratia, T. Grande, M.G., H. Gebhardt, M. Ebach, A. Wyss, J. Waters, B. Perez-Moreno, G. Cuny, A. Choudhury, M. Vences, S.H. Weitzman, L. Cavin, F. Santini, J.C. Briggs, L.M. Gahagan, Philiphe J.G. Maisey, M. Gayet, J. Alves-Gomes, G. Lecointre and L. Taverne, and particularly E. Parmentier, P. Vandewalle and M. Chardon for their helpful discussions, their criticism, their advice and their assistance.

DIOGO, R. Homoplasias, índice de consistencia y la complejidad de evolución morfológica: Peces gato como un estudio de caso para discusiones generales en filogenia y macroevolución. Int. J. Morphol., 25(4):831-837, 2007.

RESUMEN: Los peces gato constituyen un grupo cosmopolita ampliamente diversificado, el cual representa cerca de un tercio de todos los peces de agua dulce, y es uno de los taxones más diversos de vertebrados. El detallado estudio de los Siluriformes puede, de esta forma, proveer datos útiles y ejemplos ilustrativos para amplias discusiones de filogenia general y macroevolución. En esta comunicación expondré brevemente cómo el estudio de este grupo notoriamente diverso revela un ejemplo de amplia homoplasia y un complejo «mosaico» de evolución morfológica.

PALABRAS CLAVE: Peces gato; Homoplasia; Macroevolución Morfológica; Filogenia; Siluriformes; Teleosteos.

\section{REFERENCES}

Burgess, W. E. An atlas of freshwater and marine catfishes: a preliminary survey of the Siluriformes. Berkshire, TFH Publications, 1989.

Chardon, M. Anatomie comparée de l'appareil de Weber et des structures connexes chez les Siluriformes. Ann. Mus. R. Afr. Centr., 169:1-273, 1968.
Chen, X. Phylogenetic studies of the amblycipitid catfishes (Teleostei, Siluriformes) with species accounts. Unpublished PhD thesis, Duke University, 1994.

De Pinna, M. C. C. Higher-level phylogeny of Siluriformes, with a new classification of the order (Teleostei, Ostariophysi). Unpublished PhD thesis, University of New York, 1993. 
De Pinna, M. C. C. A phylogenetic analysis of the Asian catfish families Sisoridae, Akysidae and Amblycipitidae, with a hypothesis on the relationships of the Neotropical Asprenidae (Teleostei, Ostariophysi). Fieldiana (Zool.), 84: 1-82, 1996.

De Pinna, M. C. C. Phylogenetic relationships of Neotropical Siluriformes: History overview and synthesis of hypotheses. In Malabarba, L. R.; Reis, R. E.; Vari, R. P.; Lucena, Z. M. \& Lucena, C. A. S., eds. Phylogeny and Classification of Neotropical Fishes. Porto Alegre, Edipucrs, pp. 279-330, 1998.

Diogo, R. Higher-level phylogeny of Siluriformes: an overview. In Arratia, G.; Kappor, B. G.; Chardon, M. \& Diogo, R., eds. Catfishes. Enfield, Science Publishers, pp. 353-84, 2003.

Diogo, R. Morphological evolution, aptations, homoplasies, constraints, and evolutionary trends: catfishes as a case study on general phylogeny and macroevolution. Enfield, Science Publishers, 2004.

Diogo, R; Oliveira, C. \& Chardon, M. Osteology and myology of the cephalic region and pectoral girdle of Bunocephalus knerii, and a discussion on the phylogenetic relationships of the Aspredinidae (Teleostei: Siluriformes). Neth. J. Zool., 51:457-81, 2001.

Farris, J. S. The logical basis of phylogenetic analysis. In Platnick, N. I. \& Funk, V.A., eds. Advances in Cladistics. Proceedings of the second meeting of the Willi Hennig Society. New york, Columbia University Press, pp. 1$36,1983$.

Farris, J. S. The retention index and the rescaled consistency index. Cladistics, 5:417-419, 1989.

Felsenstein, J. Inferring phylogenies. Sunderland, Sinauer Associates, 2003.

Ferraris, C. J. On the interrelationships between the Aspredinidae and the Akysidae (Ostariophysi, Siluriformes). Abstracts of the 1989 Meeting, American Society of Ichthyology and Herpetology, San Francisco State University, 86, 1989.

Friel, J. P. A phylogenetic study of the Neotropical banjo catfishes (Teleostei: Siluriformes: Aspredinidae). Unpublished PhD thesis, Duke University, 1994.

Kallersjö, M; Albert, V.A. \& Farris, J. S. Homoplasy increases phylogenetic structure. Cladistics, 15:91-3, 1999.
Kitching, I. J.; Forey, P. L.; Humphries, C. J. \& Williams, D. M. Cladistics - the theory and practice of parsimony analysis. New York, Oxford University Press, 1998.

Klassen, G. J.; Mooi, R. D. \& Locke, A. Consistency indices and random data. Syst. Zool., 40:446-57, 1991.

Marques, A. C. \& Gnaspini, P. The problems of characters susceptible to parallel evolution in phylogenetic reconstructions: suggestion of a practical method and its application to cave animals. Cladistics, 17:371-81, 2001.

Mo, T. Anatomy, relationships and systematics of the Bagridae (Teleostei: Siluroidei) with a hypothesis of siluroid phylogeny. Theses Zoologicae, 17:1-216, 1991.

Sanderson, M. J. \& Donoghue, M. J. Patterns of variation in levels of homoplasy. Evolution, 43:1781-95, 1989.

Simonetta, A. M. Is parsimony a justified criterion in the assessment of possible phylogenetic reconstructions? Ital. J. Zool., 66:159-69, 1999.

Teugels, G. G. State of the art of recent siluriform systematics. In Arratia, G.; Kappor, B. G.; Chardon, M. \& Diogo, R., eds. Catfishes. Enfield, Science Publishers, pp. 317-52, 2003.

Wilkinson, M. Homoplasy and parsimony analysis. Syst. Zool., 40:105-9, 1991.

Correspondence to:

Dr. Rui Diogo,

Department of Anthropology

The George Washington University

2110 G St. NW

Washington, DC 20052

USA

Email: R.Diogo@ulg.ac.be

Received: 06-04-2006

Accepted: 26-08-2007 
